\title{
Virtual reality in HR management as a condition of innovative changes in a company
}

\author{
E. Vasilenko \\ Faculty of Economics and Management \\ St. Petersburg State Technological \\ Institute (technical university) \\ St. Petersburg, Russia \\ yesvasilenko@gmail.com
}

\begin{abstract}
The article is devoted to the study of the application of virtual reality technologies in the field of HR management as one of the conditions of innovative changes in a company. It is based on the examples of foreign companies. The article shows which problems in recruitment, onboarding and training can be solved with the help of virtual reality. Using of virtual reality in HR management demonstrates the formation of a positive image of the company as an innovative and advanced employer, an increase in responses to vacancies, as well as saving time and money for conducting interviews and assessments.
\end{abstract}

Keywords - virtual reality; human resources management; recruitment; onboarding; training; technologies; Toyota; Deutsche Bahn; Jaguar; Danone.

\section{INTRODUCTION}

The rapidly growing number of scientific, technical and information developments determines one of the most successful trends in the development of technology at the present time. The number of users of the Internet and other types of virtual reality (VR) annually experiences a positive increase. VR creates some resemblance of real life by special devices expressed in digital format. VR allows us to predict, analyze, plunge directly into the heart of an action and solve a plenty of actual problems of our time. Recent studies of Goldman Sachs Group a leading global investment banking, securities and investment management firm demonstrate the expected growth of the virtual reality technology market to 95 billion US dollars by 2025 . Fig. 1 shows a graph of which areas of the economy will be the main demand for virtual and augmented reality technologies in the future until 2025 [1]. As we may see from year to year the growth other sectors of economy shows tendency to become more equable with creative industries. But at the present time, the strongest demand for augmented and virtual reality technology comes from creative industries. Some global companies like Google, Apple, Samsung count on VR which in the near future will be able to make a new revolution in life by significantly modifying some areas of business. VR has already penetrated into HR management: many companies use these technologies to improve the practice of interaction with candidates, create engaging game tests for communications inside the company and demonstrate to competitors that they are champions of innovation.

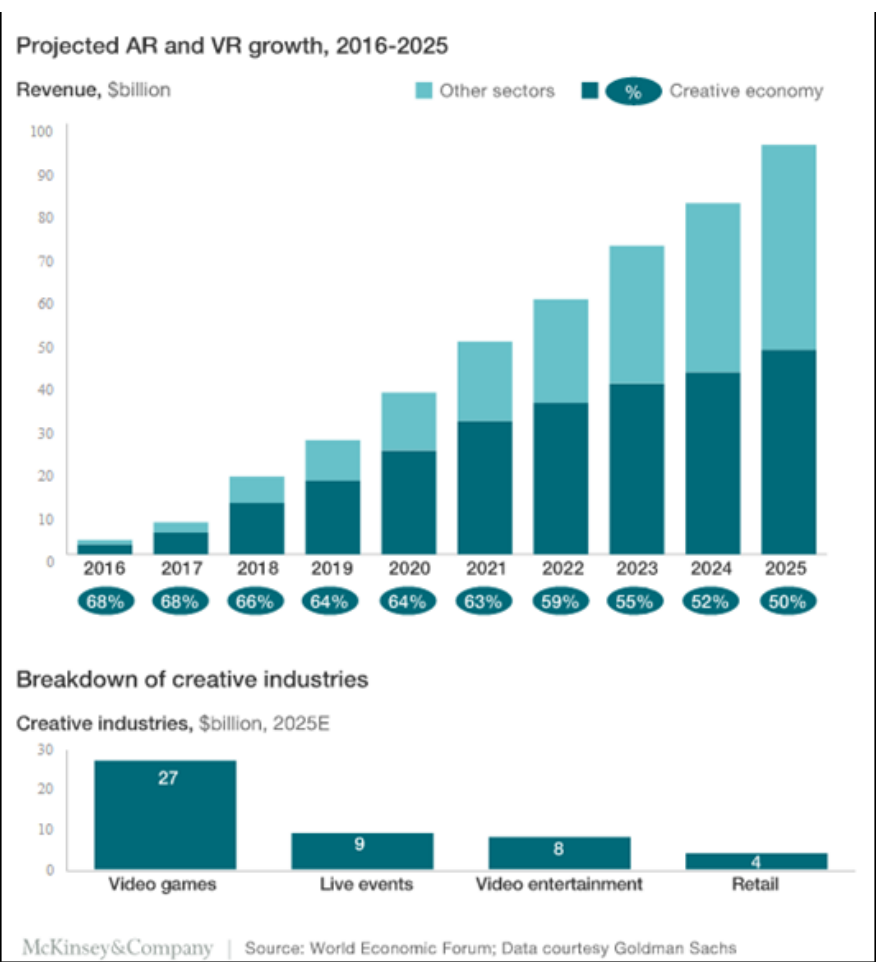

Fig. 1. Projected AR and VR growth, 2016-2025

The purpose of this article is to justify the effectiveness of using VR in the field of HR management.

\section{VR POTENTIAL}

The most far sighted corporations have started to introduce services of VR into their business processes. While Russian entrepreneurs and businessmen are reluctant to invest in the development and application of virtual technologies for the recruitment, adaptation and training of staff, foreign colleagues demonstrate successful experience of its implementation. The biggest companies in Russia show significant interest in VR technology and solutions, but the number of actual projects isn't that high - in 2015, there were 5-10 companies that began implementing VR technology into their daily business, and in 2016 that number was twice as high. Fig. 2 shows ambitious forecast of the growth of VR users platforms in Russia [4]. It means that Russian businessmen need to pay attention on foreign optimistic experience of working with VR as the 
GROWTH PREDICTION OF THE USER DATABASE FOR THE MAJOR VR PLATFORMS IN RUSSIA (MILLIONS), 2017

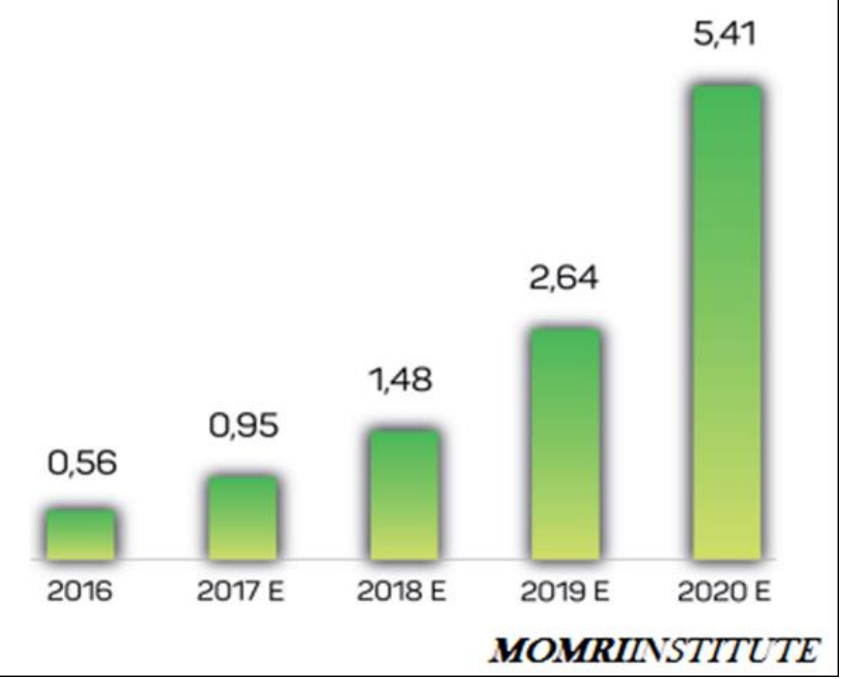

Fig. 2. Growth prediction of the user database for the major VR platforms in Russia (millions), 2017

interest of people in the country is growing from year to year. VR technology has only broadened the horizon in every aspect of HR management - from recruiting to training and communication. An example of one of the most effective implementations of VR in the recruiting campaign is the experience of the British Army. Recruitment to the Army Reserve is always challenging so it created four VR experiences based on combat training, adventure training, tank training and parachute training, which were then posted on YouTube 360. The results of this experiment were amazing: for the first month of the campaign the number of job application increased by $65 \%$ and for the second one by $41 \%$ [6]. Another example of implementing VR technologies in training process is also from military industry. In 2012, the US Army began training military officers with the help of VR technologies. The newest technologies are used in the training of pilots, infantry forces and medical officers. It allows soldiers to be in conditions as close to combat as possible without any danger to life and health. The main difficulty of this project is to provide virtual trainings with maximum realism. According to representatives of the US Air Force, the usage of virtual reality technologies significantly reduces the cost of training pilots (approximately USD 1.7 billion for 2012-2016). And in the future using VR technologies should significantly reduce the total costs of the Ministry of Defense for the training of Air Force specialists. And this is just one of many ways to apply the latest technologies in the military industry. The revenue from the sale of software for the training of military specialists is estimated at USD 500 million in 2020 and USD 1.4 billion in 2025. Soon, the Ministry of Defense will begin to purchase VR devices. However, these versions of the device will be supplied exclusively for military training and will be unavailable for broad market. And that is difficult to make long-term sales forecasts.

The Venture Reality Fund, a venture capital fund that tracks investments in the sector, reported that the number of investments in the entertainment sector in the second half of 2017 is up 79 percent compared to the same period a year ago. The VR Fund's latest report highlights more than 450 companies developing infrastructure, tools, platforms, and applications for the VR/AR ecosystem. So far this year, global investment in AR and VR is more than $\$ 2.3$ billion, higher than in any previous year [5]. These data confirm the fact that investors have a sustained interest in the development of virtual reality technologies. Company can create games using VR for adaptation process and training programs by developing the entertainment sector in the field of VR.

For instance, the Government-supported CNC Fund in France provides funding for technology producers/VR products offering grants that cover both development and production. Not so long ago, the fund supported about $40 \%$ of the cost of 500000 euros needed to produce a short film using VR [11].

So far many companies were hesitant to apply VR technology because of the complexity and extensive cost of implementation. At the end of last century some company could easily spend USD $60 \mathrm{~K}$ just for the basic equipment. Today an inexpensive VR Headset with eye-trackers and voice recognition, a smartphone, an affordable 360 camera and content tooling are enough to not only enjoy, but also create VR content. Some analytics predict a bright future for VR in recruitment as the costs of VR headsets and consoles, like the popular Oculus Rift, HTC Vive and Sony PlayStation VR continue to fall. Access to VR will be bolstered by new 360-degree cameras available for around USD 500, such as Samsung's Gear 360 camera and the LG360 Cam [3]. There are today also easy accessible apps to help create content. Therefore the development, usage and deployment of VR applications in a business environment has become simple and affordable. Some companies choose to make and develop their own VR's and others use one of the many providers in this field.

In view of this, the study of the advantages of using virtual reality technologies in HR management is an extremely relevant task. In addition, it is important to note that at the present time there is a lack of relevant scientific information and researches which contributes to the qualitative development of the appliance of VR technologies in HR management.

\section{PUTTING VR INTO PRACTICE}

Every day HR managers solve a lot of problems and tasks: how to hire in a short time an ambitious candidate, what kind of search platform to use and how to attract new talents in order to make the work of the whole team comfortable and productive. And now is the moment when all these tasks can be solved with the least labor and time costs and the greatest success. Large corporations and agile startups use virtual technologies from recruiting to training and networking. Let's consider one of the most sought after areas in HR management with the use of VR technology. And this is recruitment. Technology is allowing businesses to recruit candidates without the usual expense and hassle as newspaper job listings, physical CVs, and face-to-face interviews become a relic of the analogue past. Indeed, the application of digital technologies such as virtual reality, social media and high-definition video in recruitment is resulting in big changes taking place across the human resources industry [3]. If some time ago the stability and guarantees were important for candidates, now the millenniums are looking for freedom for realization of creative ideas, flexibility of the work process, working hours and approbation of their own ideas, as well as complex interesting tasks. Toyota Motor Corporation has launched a virtual tour on the InstaVR platform on its own campus where everybody can see everything that happens day 
by day through a 360 tour [2]. And a German railway company Deutsche Bahn AG has installed at one of the Career Fair some stands with the opportunity to put on VR headset, choose the location and find out what the company is doing in any part of the country. This innovative approach has positively affected the growth of job applications, its quality and awareness of potential candidates. Similar results were achieved by another worldknown company Jaguar Land Rover - the UK's largest car manufacturer. In cooperation with the popular music group Gorillaz they launched a free app with elements of augmented reality to fill more than a thousand vacancies. According to the managers of talents of these companies, virtual reality technologies make it possible to identify the candidate's interest, resourcefulness, and skills of solving problems. Moreover, this mechanism is unique; it attracts progressive and ambitious candidates, creates an excitement for a company and finally allows company to stand out for packed Career Fair among competitors [1]. Let's look at the Russian common business space. A world leading food company Danone on one of its development (recruiting) programs Surf Danone at the online stage uses the VCV service - a video interview. The system is quite simple: the candidate receives an invitation from the HR manager and answers the questions. His answers are written down and sent directly to the HR manager. The peculiarity of this system is that the candidate does not see questions in advance. He has only 15 seconds to read the question and then the camera and the microphone turn on. This form of interviewing has many positive aspects for the employer. First, the company saves time and money for calling the applicants with the purpose of inviting them to an interview. Secondly, it saves time and effort of HR managers to hold hundreds of meetings. In the third place, it allows recruiters to watch video interview an unlimited number of times. With the help of virtual reality, recruiters can evaluate the response of candidates to questions and analyze their non-verbal communication. The ability to screen candidates faster and more effectively means fewer man hours attributed at the recruitment stage and more time spent on maintaining a strong culture and retaining great talent [3].

Another important field in HR management of a company is onboarding. People in the human resources department are often overworked, and orientation and onboarding of new employees don't make it any easier. Using a virtual reality set up, they can let new hires experience being welcomed by the CEO, meet fellow colleagues and get acquainted with the particulars of the organization. It can also be a perfect way to get an employee who's going to work remotely, connect with the organization [7]. VR technology can improve the onboarding experience for new employees significantly by various apps and devices. Some companies use chat bots in their work. Chat bots are connected to your portal, to CRM, to e-lerning systems, so that an employee using them can find any information. For example, when new employee just starts working in the company all instructions are sent in dialogue mode. A script is written and the bot answers the user's questions. And the bot takes this information from the portal from the desired section.

Virtual reality technology can be used to simulate real world scenarios and situations to replicate situations and help employees more easily prepare for various situations. Organizations can even gamify the whole experience of employees. They could use VR to make the environment more competitive: companies can simulate a sales scenario, for example, a customer wandering through the shop floor, deciding between models. Organizations can design competitions, and grade sales employees based on various merits such as price point achievement, close-rate efficiency, etc. to induce a more performance-based environment into the organization. Take the Walmart example of implementing the Employee Onboarding (Training) Game as a company's VR strategy. The director of the HR department decided to introduce a program with virtual reality technologies based on the game in the training system. The Game assumes that a new Walmart store manager who has never seen a Black Friday sale in action will practice his/her skills. To make him/her understand the dynamics of such a busy day, put through an immersive hands-on training; testing his/her ability to handle stress from the horde of excited customers, his/her leadership skills to direct and manage company's subordinates, even his/her emotional intelligence like empathy and tolerance. His/her actions, emotional and behavioral responses to every situation is then captured and measured. This is done by integrating VR hardware with eye tracking, voice recognition, gestures and position tracking and biometric technologies. Good results are shown after the first experience.

Also it is important to speak about education and we cannot ignore educational programs for people who will work in the VR market. In Russia, so far, there are no full-fledged state programs of that type. However, even now there are large programs of additional education. For example, the first in the country school Academy of Realities for training VR-specialists. Also there are professional video lectures as an example from Microsoft.

\section{THE FUTURE}

So far, analysts, developers and experts believe that virtual reality technologies have not yet reached their peak. Every year, investments in the development and designing of virtual reality technologies are increasing. This trend is cause of the fact that VR does not just simplify human activities, it makes new opportunities that were previously unavailable $[8,9]$. Certainly, it's too early to talk about the perfection of virtual reality technologies but by virtue of them many employers can implement the fundamental spheres of HR management in an absolutely innovative direction inaccessible earlier [6]. HR management is gradually becoming more and more technological [6]. And it has a qualitative effect on the work of the company: the processes are automated and company saves money and time. As the result there is no longer any need to pay for business trips (travel and accommodation) and all kinds of training in other cities and countries of regional employees. VR will drastically reduce the economic and time costs for staff training. And using VR in an assessment will approximate the candidate's skills in a particular job to the most realistic. With devices providing VR candidates can freely navigate, move, move objects and solve real problems, but already in virtual space. These experiences help a business stand out from the crowd in a competitive recruitment environment [3]. It is obvious that not every top management of company is ready to accept such innovations in its work. Companies are still unwilling to invest a significant chunk in VR experiences unless they have a tangible way of measuring effectiveness. For some it is easier to say that using this innovations referring to the complexity of implementation, constant improvements and cost. The pay-off for companies prioritising digital in today's ultracompetitive labour market outweighs any potential risks. While cutting-edge technologies represent potentially large cost savings for HR departments, they also present new challenges 
for recruiters, many of whom are unfamiliar with the latest industry tech [4]. At least it's time for HR to take charge and build a VR strategy. However, technologies can surprise and probably in a few years HR-processes will become inextricably linked with VR.

\section{CONCLUSIONS}

The article gives examples of the application of virtual reality technologies in HR management and presents developments that are already actively used in some companies. Despite that kind of a success and demand for VR, there have not been done any significant researches yet. However, a definite basis for designing and developing programs using virtual reality technologies for all areas of HR management has already been formed

\section{REFERENCES}

[1] "Augmented and virtual reality: the promise and peril of immersive technologies," (2017). Available at: https://www.weforum.org/agenda/2017/09/augmented-and-virtualreality-will-change-how-we-create-and-consume-and-bring-new-risks (accessed 22 February 2018).

[2] Iljashenko, O., Bagaeva, I., Levina, A. Strategy for establishment of personnel KPI at health care organization digital transformation(2019) IOP Conference Series: Materials Science and Engineering, 497 (1), № 012029.

[3] "The future of Virtual Reality in HR," (2017). Available at: https://www.theceomagazine.com/business/future-virtual-reality-hr/ (accessed 22 February 2018)

[4] "The virtual reality market in Russia 2016," (2017). Available at: http://momri.org/wp-content/uploads/2017/04/MOMRI.-VR-market-inRussia.-April-2017-eng.pdf (accessed 19 February 2018).

[5] "The VR Fund: Entertainment VR investments jump 79\% in second half of 2017," (2017). Available at: https://venturebeat.com/2017/11/19/the- vr-fund-entertainment-vr-investments-jump-79-in-second-half/ (accessed 21 January 2018).

[6] “Trendy uhodyashchego goda: kak virtual'naya real'nost' izmenila HR (Trends of the last year: how virtual reality has changed HR)," Available at: https://rb.ru/opinion/vr-hr/ (accessed 14 February 2018).

[7] "Virtual Reality \& HR Function," (2015). Available at: https://www.thehrdigest.com/virtual-reality-hr-function/ (accessed 22 February 2018)

[8] Bagaeva, I., Iliashenko, O., Borremans, A. Theoretical and methodological aspects of the competence approach to the evaluation of the organization's personnel (2018) MATEC Web of Conferences, 193, № 05060 .

[9] Kozlov, A., Teslya, A. (2017) Human factors for development of corporate internal social investments Portfolio. Advances in Intelligent Systems and Computing, 2017.

[10] "Virtual'naya real'nost' (Virtual reality)," Available at: http://www.tadviser.ru/index.php/Статья:Виртуальная реальность (accessed 20 January 2018).

[11] Bril A.R., Kalinina O.V., Ilin I.V. (2017) Economic Analysis of Projects in the Improvement of the HR Management System of Enterprises // Proceedings of the 29th International Business Information Management Association Conference - Sustainable Economic Growth, Education Excellence, and Innovation Management through Vision 2020. Pp. 2268 2277.

[12] Klochkov, Y., Klochkova, E., Volgina, A., \& Dementiev, S. (2016). Human factor in quality function deployment. Paper presented at the Proceedings - 2nd International Symposium on Stochastic Models in Reliability Engineering, Life Science, and Operations Management, SMRLO 2016, 466-468.

[13] "21st-century HR: How VR is changing the face of training," (2017) Available at: https://www.samsung.com/uk/business/vr-for-businesssolutions/21 st-century-hr-how-vr-is-changing-the-face-of-training/ (accessed 6 February 2018). 